\title{
Dissociation of Primary and Secondary Reward-Relevant Limbic Nuclei in an Animal Model of Relapse
}

Jeffrey W. Grimm, Ph.D., and Ronald E. See, Ph.D.

The neural substrates underlying relapse to drug-seeking behavior after chronic drug abuse may differ from those underlying immediate drug-taking behavior. In a model of relapse to drug-seeking behavior following chronic cocaine self-administration and prolonged extinction, we have previously shown that rats will significantly reinstate lever responding for either primary reward (cocaine) or secondary reward (tone + light stimulus previously paired with cocaine). In the present study, we utilized reversible inactivation of discrete brain nuclei with tetrodotoxin (TTX) in order to examine the neural substrates mediating primary and secondary cocaine reward in rats allowed two weeks of cocaine self-administration. After one week of daily extinction sessions, bilateral inactivation of the basolateral amygdala resulted in significant attenuation of lever pressing for a cocaine-conditioned reward (tone + light). Following three more days of extinction, bilateral TTX inactivation of the basolateral amygdala had no effect on the reinstatement of cocaine self-administration. In contrast, TTX inactivation of the nucleus accumbens produced the exact opposite effects, with significant blockade of primary reward (cocaine alone), but not secondary reward (tone + light). Thus, cocaine-conditioned reward is neuroanatomically dissociated from primary cocaine reward.

[Neuropsychopharmacology 22:473-479, 2000]

Published by Elsevier Science Inc.
KEY WORDS: Basolateral amygdala; Cocaine; Nucleus Accumbens; Relapse; Reward; Self-administration

Treatment of addiction to drugs such as cocaine is problematic due to the propensity of dependent individuals to return to drug-taking, even after prolonged withdrawal. This relapse to drug-taking may represent the ultimate behavior in a preceding chain of events not maintained by the drug, but by contingencies established between the drug and environmental stimuli

From the Intramural Research Program, National Institute on Drug Abuse, Baltimore, MD (JWG); and Department of Physiology and Neuroscience, Medical University of South Carolina, Charleston, SC (RES).

Address correspondence to: Ronald E. See, Ph.D., Department of Physiology and Neuroscience, 167 Ashley Avenue, Suite 614, Medical University of South Carolina, Charleston, SC, 29425.

Received July 28, 1999; revised November 3, 1999; accepted December 1, 1999. during the active period of drug use. Clinical studies have described how drug-paired stimuli can produce subjective reports of craving in cocaine addicts (Ehrman et al. 1992), as well as reliable changes in physiological measures of arousal (Johnson et al. 1998) and activation of limbic brain regions associated with the processing of reward (Childress et al. 1999). In addition, a number of animal models have demonstrated various forms of cocaine-paired stimulus conditioning with rats trained to self-administer drugs of abuse (Davis and Smith 1976; de Wit and Stewart 1981; Markou et al. 1993; Weissenborn et al. 1995; Meil and See 1996).

The nucleus accumbens and amygdala are two brain structures shown to be critically involved in appetitive behaviors (Everitt and Robbins 1992; Gaffan 1992), including drug-seeking behavior (Whitelaw et al. 1996; Meil and See 1997; Wise 1998). Indeed, in human brain imaging studies, cocaine ingestion has been associated with activation of 
the nucleus accumbens (Breiter et al. 1997), whereas metabolic changes in the amygdala have been associated with presentations of cocaine-related stimuli and self-reported craving (Grant et al. 1996; Childress et al. 1999). Efferent projections from the amygdala to the nucleus accumbens have been suggested to mediate the perception of motivationally relevant environmental stimuli into goal-directed behaviors (Mogenson et al. 1980, 1993). Thus, amygdalaraccumbal interactions may play a critical role in the manifestation of craving and drug-seeking behaviors seen after prolonged drug abuse.

The purpose of the present study was to examine the contributions of the basolateral amygdala and the nucleus accumbens in an animal model of relapse that incorporates assessment of both primary and secondary (conditioned) cocaine reward. Reward presentations were dependent on the behavior of the animal (response contingent presentations) and primary and secondary reward presentations occurred on separate test days in order to avoid the confound of animals seeking conditioned cocaine reward under the influence of the effects of cocaine itself. Intracranial infusion of tetrodotoxin (TTX), a sodium channel blocker, was used to produce reversible inactivation of the basolateral amygdala or the nucleus accumbens. This form of temporary neural interruption allows examination of the loss of a structure in a circuit without the degeneration of secondary structures and compensation by spared tissue that can occur with traditional lesion procedures (Zhuravin et al. 1994).

\section{METHODS}

\section{Self-Administration Procedures}

Male Sprague-Dawley rats (3-4 months, $350-450$ g; Taconic) were trained to press the right lever for $45 \mathrm{mg}$ food pellets in operant chambers $(30 \times 20 \times 24 \mathrm{~cm}$; Med Associates) enclosed in sound-attenuated cabinets with ventilation fans. Intra-jugular catheters and cranial cannulae were then implanted into the rats. Jugular catheter construction and implantation were based on previously described procedures (Caine et al. 1993). Briefly, catheters were constructed by gluing Silastic tubing (ID $=0.64 \mathrm{~mm} ; \mathrm{OD}=1.19 \mathrm{~mm}$; Dow Corning) to an external guide cannulae (Plastics One). The cannulae were then glued to polypropylene mesh with cranioplastic cement. The free end of the Silastic was inserted into the right jugular vein and secured with 4.0 silk sutures around the venous tissue. The catheters exited dorsally on the animals' backs. Dummy stylets were inserted into the catheters when rats were not connected to infusion pumps. Catheters were flushed twice daily with heparinized saline and an antibiotic (Timentin) for 5 days following surgery. For each self-administration session, rats were flushed with $0.1 \mathrm{ml}$ of heparinized sa- line before sessions began and with $0.1 \mathrm{ml}$ of heparinized saline and $0.1 \mathrm{ml}$ of Timentin after each session.

Following four days of recovery from surgery, rats began daily cocaine self-administration sessions $(3 \mathrm{~h}$ duration). A response on the right (active) lever produced a compound stimulus consisting of a white stimulus light + a tone $(2 \mathrm{kHz}, 15 \mathrm{~dB}$ over ambient noise) and an intravenous injection of cocaine $\mathrm{HCl}(0.33 \mathrm{mg} /$ $0.05 \mathrm{ml}$; dissolved in sterile saline) delivered by an infusion pump (Med Associates) located outside of the cabinet. The compound stimulus ( $5 \mathrm{~s}$ duration) occurred simultaneously with cocaine injection and was followed by a $40 \mathrm{~s}$ time out period, during which lever responding had no programmed consequences, but lever responses were recorded. Responses on the left (inactive) lever were recorded, but had no programmed consequences. After 14 days of self-administration, animals were exposed to seven days of extinction sessions (lever responding had no programmed consequences). The following $3 \mathrm{~h}$ session was a reinstatement day where contingent access to the cocaine-related stimulus (tone + light) was allowed (but no cocaine delivery). Three further extinction days were followed by a final day on which cocaine, but no tone + light, was delivered following a right lever response. Data from the basolateral amygdala and nucleus accumbens groups were analyzed separately. Two-way repeated measures analysis of variance (RM-ANOVA) was used to assess changes in lever responding over time (day 14 of self-administration, days $1,7,9$, and 11 of extinction, and the twotest days (tone + light access and cocaine access) and between vehicle and TTX groups. Following a significant F, the Student Newman-Keuls test was used for appropriate post hoc comparisons. The minimum criterion for significant differences was set at $p<.05$.

\section{Intracranial Infusions}

Immediately following catheter implantation, rats were placed in a stereotaxic device (Stoelting) and stainless steel guide cannulae ( $22 \mathrm{~g}$ ) were bilaterally implanted using set coordinates (Paxinos and Watson 1997) into the basolateral amygdala (A/P $-2.5, \mathrm{~L} \pm 5.0, \mathrm{~V}-7.5)$ or the nucleus accumbens $(\mathrm{A} / \mathrm{P}+1.2, \mathrm{~L} \pm 1.5, \mathrm{~V}-6.5)$.

Immediately prior to beginning a test day session, infusion cannulae ( $28 \mathrm{~g})$ were bilaterally inserted such that $1 \mathrm{~mm}$ of each tip extended past the end of the guide cannulae. TTX (tetrodotoxin citrate; Tocris) was dissolved in a phosphate buffered saline vehicle (both solutions adjusted to $\mathrm{pH} 7.0)$. Vehicle or TTX $(6 \mathrm{ng} / \mu \mathrm{l})$ were infused at a volume of $0.5 \mu \mathrm{l} /$ side delivered over $1 \mathrm{~min}$. Cannulae were left in place for $1 \mathrm{~min}$ following infusions, after which the subject was placed in the selfadministration chamber. In pilot studies, this dose of TTX microinjected into either the basolateral amygdala or nucleus accumbens failed to affect basal- or cocaine- 
stimulated locomotor behavior. After the final session, rats were given an overdose of Equithesin and perfused with saline, followed by $10 \%$ formaldehyde solution. The brains were extracted and tissue cut in $75 \mu \mathrm{m}$ coronal sections, followed by staining with cresyl violet. Tissue sections were then inspected for infusion cannulae tip placements.

All animal care and use procedures conformed to the Guide for the Care and Use of Laboratory Animals $(\mathrm{NIH})$ and were approved by an Institutional Animal Care and Use Committee.

\section{RESULTS}

Rats implanted with jugular catheters and allowed to self-administer daily cocaine showed steady rates of lever responding for cocaine infusions (Figure 1). No significant differences were found between groups for right lever responding during the two weeks of chronic cocaine self-administration. Statistical analysis revealed a significant effect of time $(\mathrm{F}(6,82)=15.84 ; p<.05)$, and a significant interaction $(\mathrm{F}(6,82)=2.25 ; p<.05)$ for the basolateral amygdala group, and a significant effect of drug $(\mathrm{F}(1,15)=6.71 ; p<.05)$, time $(\mathrm{F}(6,84)=13.07 ; p<$ $.001)$, and a significant interaction $(\mathrm{F}(6,84)=2.55 ; p<$ $.05)$ for the nucleus accumbens group. One week of extinction sessions, during which time cocaine was unavailable, resulted in a significant decrease in lever responding for both groups $(p<.05$; comparison between extinction day 1 and day 7 ).

On two separate test days after extinction sessions, rats given bilateral vehicle microinjections in the basolateral amygdala (Figure 1) or the nucleus accumbens (Figure 1) reinstated high levels of lever responding for presentation of the compound stimulus (tone + light) previously associated with cocaine (secondary reward), or cocaine infusions alone (primary reward) $(p<.05$; comparison between previous extinction day and subsequent test day). These results confirm our previous data showing a robust reinstatement of responding for primary or secondary reward after prolonged extinction and withdrawal from self-administered cocaine (Meil and See 1996; See et al. 1999).

Bilateral TTX inactivation of the basolateral amygdala selectively disrupted lever responding for the tone + light $(p<.05)$, but had no effect on lever responding for cocaine alone when compared to vehicle microinjection (Figure 1). The total dose of cocaine received on the second test day did not differ between the two basolateral amygdala groups (mean \pm SEM: vehicle $=20.4 \pm 2.5 \mathrm{mg} / \mathrm{kg} ;$ TTX $=24.7 \pm 1.0 \mathrm{mg} / \mathrm{kg} ; \mathrm{t}(14)=$ $1.60 ; p>.05)$. In marked contrast to bilateral TTX inactivation of the basolateral amygdala, bilateral TTX inactivation of the nucleus accumbens had no significant effect on lever responding for the tone + light on test day
1 , but significantly attenuated lever responding ( $p<$ .05 ) for cocaine on test day 2 (Figure 1). The total dose of cocaine received on the second test day was also significantly different $(p<.05)$ between the two nucleus accumbens groups (mean \pm SEM: vehicle $=25.7 \pm 2.8$ $\mathrm{mg} / \mathrm{kg} ;$ TTX $=11.2 \pm 1.7 \mathrm{mg} / \mathrm{kg} ; \mathrm{t}(15)=4.54 ; p<.001)$. Responding on the left (inactive) lever was negligible over the course of the experiments (data not shown).

TTX microinjections in both groups did not simply
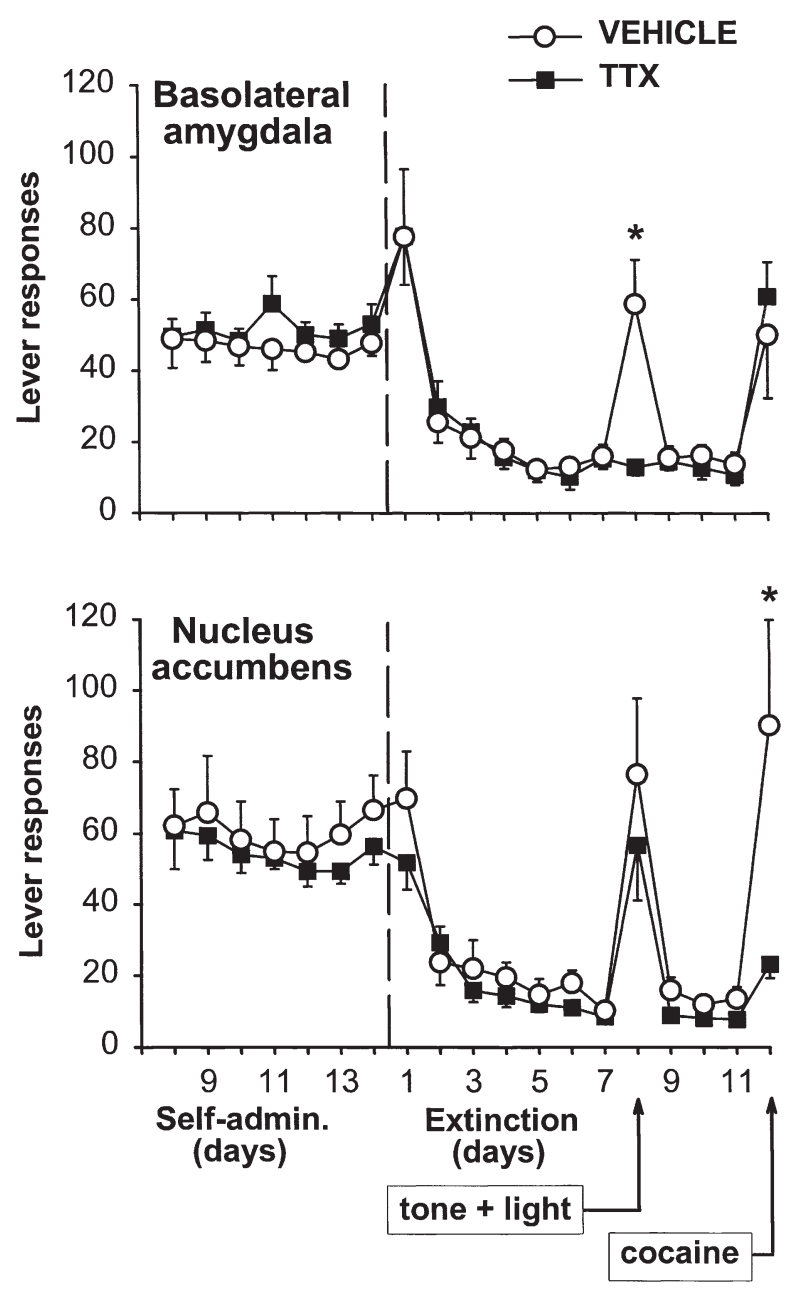

Figure 1. Responses on the cocaine-paired right lever (mean \pm SEM) during the last week of self-administration, extinction, and the two test days. Animals were microinjected with vehicle or TTX immediately prior to test days indicated as "tone + light" and "cocaine". Top: Lever responses for rats implanted with bilateral cannulae in the basolateral amygdala and microinjected with vehicle $(n=8)$ or TTX $(n=8)$. Rats microinjected with TTX failed to reinstate responding for the tone + light $(p<.05)$. Bottom: Lever responses for rats implanted with bilateral cannulae in the nucleus accumbens and microinjected with vehicle $(n=8)$ or TTX $(n=9)$. Responding of TTX-treated rats for the primary (cocaine) reward was selectively attenuated when compared to vehicle infusion $(p<.05) .{ }^{*}$ indicates a significant between group difference for the test session; $p<.05$. 
induce behavioral inactivation, as evidenced by the fact that the magnitude and patterns of responding were not different from vehicle-treated rats on the tone + light test day (nucleus accumbens) or the cocaine test day (basolateral amygdala). Representative individual records across the $3 \mathrm{~h}$ test session illustrate the selective attenuation of lever responding after TTX microinjection in the basolateral amygdala on test day 1 (Figure 2) and the nucleus accumbens on test day 2 (Figure 2).

Following all behavioral testing, histological examination of cresyl-stained tissue sections showed that in-

\section{Basolateral amygdala}
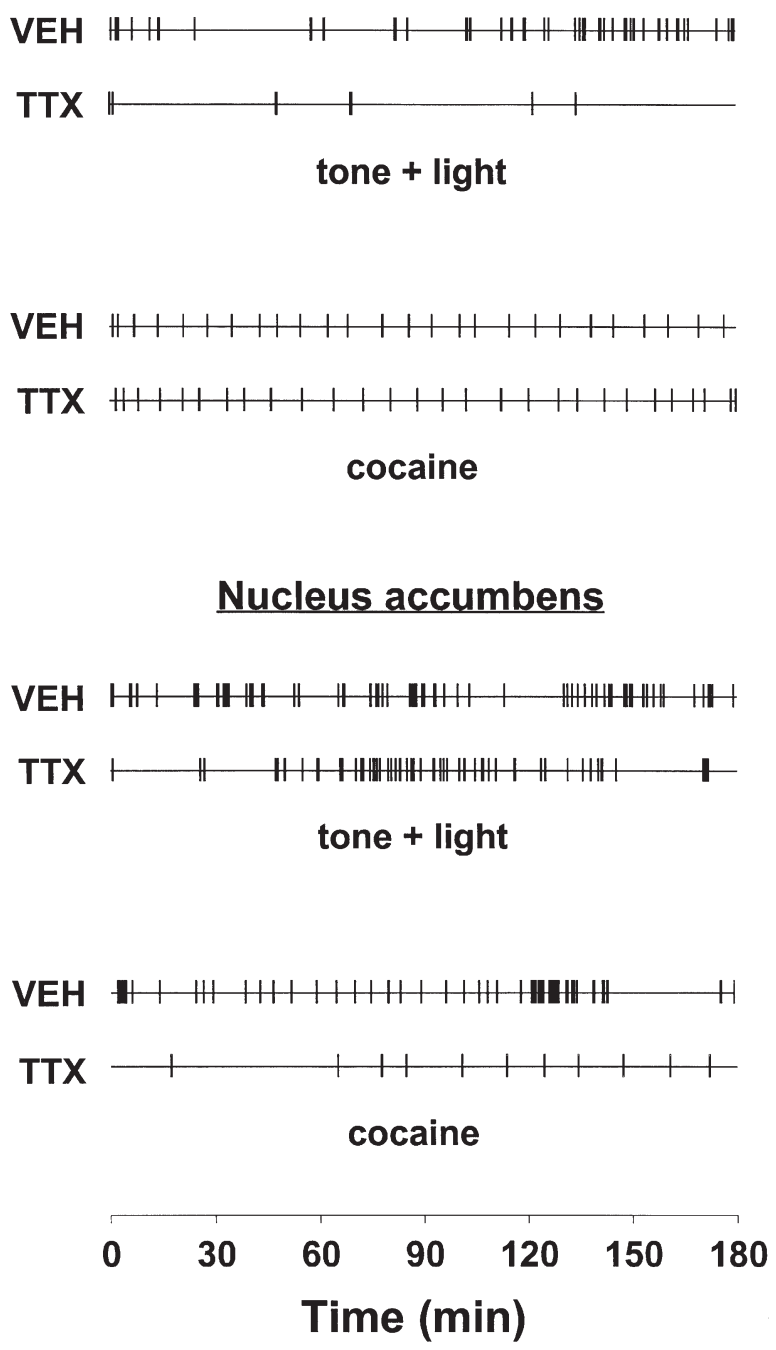

Figure 2. Lever response records for individual subjects selected to represent the general pattern after bilateral microinjections in the basolateral amygdala (top) or the nucleus accumbens (bottom). Each vertical mark represents one lever press. The same subject is depicted for both test sessions of tone + light and cocaine. The first line in each depiction is the vehicle infused rat (VEH) and the second line is the TTX infused rat. tracranial microinjection sites were localized throughout the basolateral amygdala (Figure 3) and ranging from the central core to the core/shell boundary of the nucleus accumbens (Figure 3).

\section{DISCUSSION}

These results demonstrate a striking dissociation of structure and function in a novel extinction/relapse paradigm of drug craving, whereby the basolateral amygdala is implicated in reinstatement of cocaine-conditioned reward and the nucleus accumbens plays a role in primary cocaine reward. The selective decrease in responding for conditioned reward following bilateral TTX microinjections into the basolateral amygdala confirms previous findings that excitatory amino acid

\section{Basolateral amygdala}

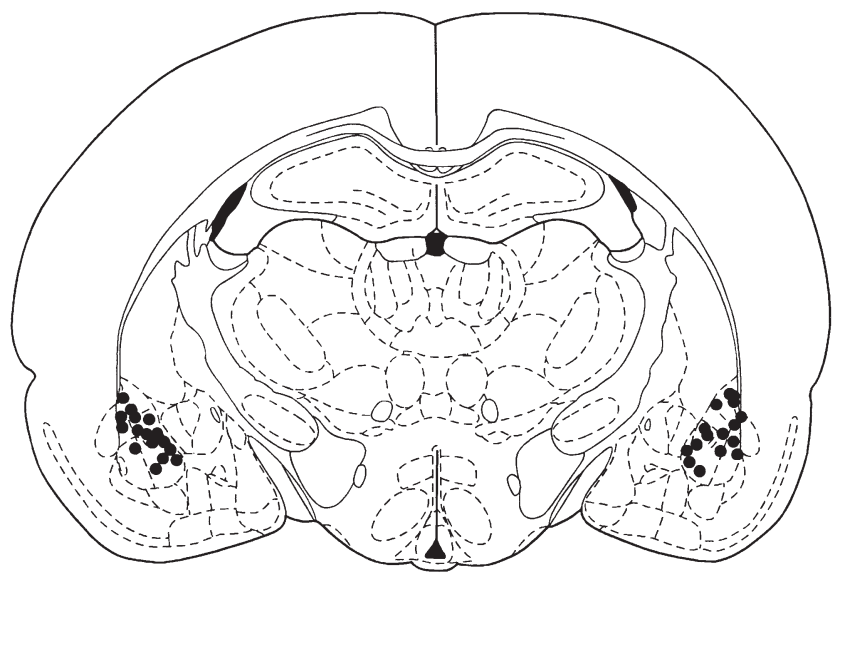

\section{Nucleus accumbens}

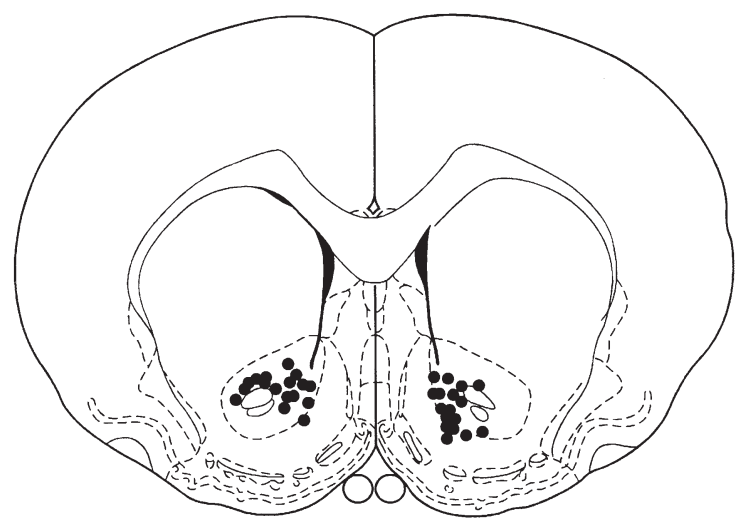

Figure 3. Microinjection tip placements in the basolateral amygdala (top) and the nucleus accumbens (bottom). Distance from bregma in $\mathrm{mm}$ : basolateral amygdala -2.56 ; nucleus accumbens +1.20 . 
lesions of this structure attenuate responding for cocaine-paired stimuli, but do not affect maintenance of cocaine self-administration (Whitelaw et al. 1996; Meil and See 1997). The attenuation of cocaine self-administration following microinjections of TTX into the nucleus accumbens parallels a number of studies in which cocaine self-administration is significantly decreased following dopamine depletion or excitatory amino acid lesions (Roberts et al. 1977; Zito et al. 1985). This decrease in behavior might be described as an attenuation in the rewarding properties of cocaine.

Recent studies have found increased responding on a drug-paired lever following microinjection of either glutamate receptor agonists (Cornish et al. 1999) or cAMP-dependent protein kinase inhibitors (Self et al. 1998) in the nucleus accumbens, contrasting with the present results. It is possible that these manipulations led to stimulation of accumbens-mediated circuitry in a manner similar to an intra-accumbens infusion of dopamine or by cocaine itself, as demonstrated in studies which have shown that a single priming dose of cocaine will increase lever responding (de Wit and Stewart 1981). Depending upon how increased lever responding (a measure of drug-seeking behavior) is initiated following extinction, the nucleus accumbens may be sufficient in "conditioned reward-like" responding, but not necessary in responding for conditioned reward. In the paradigm utilized in the present study, rats will robustly reinstate lever pressing if presented with a contingent, but not a noncontingent, stimulus previously associated with cocaine (unpublished data). In addition, we have demonstrated (See et al. 1999) that such responding is very specific for the cocaine paired stimulus (e.g., rats will not press for a tone or light alone following training with a tone + light compound).

Responding for cocaine-conditioned reward after extinction, as evaluated in the present study, appears to be mediated outside of the nucleus accumbens. These results imply that different neural processes may contribute to relapse to drug-seeking behavior in cocaine addicts when exposed to conditioned environmental stimuli vs. renewed consumption of the drug itself. However, a number of other experimental paradigms have shown a critical role of the nucleus accumbens in conditioned reward (for recent review, see Sutton and Beninger 1999). While we did not differentiate between accumbal subregions, the different subregions of the nucleus accumbens may have diverse roles in mediating conditioned reward.

A recent study localized Pavlovian components of learned behavior (discriminative approach to a stimulus light and sucrose containing magazine during CSUS pairings) to the nucleus accumbens core subregion and the potentiative effects of amphetamine to the nucleus accumbens shell subregion (Parkinson et al. 1999). The nucleus accumbens core thus appears to have a critical role in some aspects of the acquisition of responding for conditioned reward, while DA activation in the shell region potently enhances responding for the conditioned reward. However, these results did not show the nucleus accumbens to be necessary for conditioned reward as regardless of lesion subregion, rats responded for conditioned reward. Other studies in support of this include: a) the lack of elimination of conditioned reward by 6-OHDA lesions of the nucleus accumbens (Taylor and Robbins 1986); and b) failure of NMDA antagonist infusion into the nucleus accumbens core to affect responding for conditioned reward at a dose that disrupted food consumption (Kelley et al. 1997). Finally, it has recently been reported that paired environmental cues induce c-fos immunoreactivity in the amygdala and prefrontal cortex, but not the nucleus accumbens, of rats during reinstatement of lever responding after prolonged extinction from cocaine selfadministration (Ciccocioppo et al. 1999).

The present study extends on previous findings using excitatory amino acid lesions of the basolateral amygdala, which resulted in attenuation of conditioned reward, but not cocaine self-administration (Meil and See 1997). Replication of these findings using a reversible inactivation technique indicates that these previous results were likely not due to changes (damage or compensation) in nuclei distal to the basolateral amygdala in the days following recovery from the lesion surgery.

TTX is a voltage-dependent sodium channel blocker, which inhibits impulse generation and neural conductance (Narahashi 1972). TTX has been utilized as a reversible inactivating agent in several behavioral studies in rats requiring a within-subject design such as that utilized in the present study (Harlan et al. 1983; Roldan and Bures 1994; Brozek et al. 1996). While our study did not include a cross-over design to specifically investigate reversibility of function following TTX, the duration of action of TTX within the range of the dose we utilized has been shown to be less than $24 \mathrm{~h}$ (Harlan et al. 1983; Zhuravin and Bures 1991) and recovery of multiunit neuronal activity within this time frame has been demonstrated following TTX administration (Harlan et al. 1983).

We also did not find the use of TTX associated with any obvious cell damage (e.g. excessive gliosis around injector tip or cavitation). We did not directly assess the extent of the spread of TTX. However, a previous study attempted to quantify larger infusions ( $1 \mu$ l per site) and indicated a spread with a radius of approximately $1 \mathrm{~mm}$ (Zhuravin et al. 1994). Therefore, it is likely that our injections of half of that volume were limited to tissue inclusive of the basolateral amygdala. With variability in tip placements, and due to the fact that the actions of TTX are not specific to any particular receptor or intracellular message pathway (e.g. glutamate agonist or cAMP-dependent protein kinase inhibitor), infusion likely blocked the activity of multiple axons of pas- 
sage. In this case, TTX could have limited the activity of nearby nuclei, including the central nucleus of the amygdala. It should be noted, however, that the basolateral amygdala has been shown to be a critical substrate of conditioned reward in paradigms other than drugs of abuse, including sexual (Everitt et al. 1989) and food (Everitt et al. 1991; Burns et al. 1993) rewards. Finally, the data clearly indicate that TTX selectively affected reward processes and did not simply induce locomotor or discrimination deficits. Specifically, TTX did not affect responding for cocaine in the rats microinjected into the basolateral amygdala, suggesting a lack of any motor problem. In addition, responding was particular to the cocaine lever, with no increase in responding on the inactive lever. The ability of the rats to discriminate the appropriate manipulandum was intact. Similar results were observed for rats microinjected with TTX in the nucleus accumbens; responding for the conditioned reward was not affected, nor was there any increase in responding on the inactive lever.

The results of the present study suggest the possibility that cocaine-conditioned reward might involve projections of the basolateral amygdala to regions other than the nucleus accumbens. For example, there is evidence of robust projections from the amygdala directly to the ventral pallidum (Maslowski-Cobuzzi and Napier 1994), and cocaine place preference has been established with microinjections of cocaine in the ventral pallidum (Gong et al. 1996). Tract tracing studies also indicate heavy projections from the amygdala to the mediodorsal nucleus of the thalamus (McDonald 1987). Monkeys trained to respond for a conditioned visual reward paired with food had performance deficits following bilateral amygdala lesions, but unilateral, asymmetric amygdala/nucleus accumbens lesions produced no deficit (Gaffan et al. 1993). Monkeys with unilateral, symmetric lesions of the amygdala and mediodorsal thalamus, however, had greater deficits and the animals with the greatest deficits had a lesion of the amygdala on one side of the brain and a combined lesion of the mediodorsal thalamus and ventromedial prefrontal cortex on the contralateral side. Gaffan (1992) suggested that such lesions lead to a disconnection between the unlearned intrinsic value of the reward from the sensory attributes of its delivery.

The importance of other cortical structures in conditioned reward is supported by a recent study (Schoenbaum et al. 1999) which showed an interdependence of activation of orbitofrontal cortex and amygdala neurons in the learning of a rewarding odor, and studies of human cocaine addicts in which the prefrontal or cingulate cortices are highly activated in the presence of cocaine associated cues (Grant et al. 1996; Childress et al. 1999). Understanding these multiple substrates of the conditioned reward circuitry of addiction may facilitate treatment of craving and relapse across a variety of drugs of abuse.

\section{ACKNOWLEDGMENTS}

This work was supported by the National Institute on Drug Abuse (DA-10462). We thank R.H. Fong for technical assistance and P.W. Kalivas, P.J. Kruzich, B.A. Sorg, and R.A. Wise for critical reading of earlier versions of this manuscript.

\section{REFERENCES}

Breiter HC, Gollub RL, Weisskoff RM, Kennedy DN, Makris N, Berke JD, Goodman JM, Kantor HL, Gastfriend DR, Riorden JP, Mathew RT, Rosen BR, Hyman SE (1997): Acute effects of cocaine on human brain activity and emotion. Neuron 19:591-611

Brozek G, Zhuravin IA, Megirian D, Bures J (1996): Localization of the central rhythm generator involved in spontaneous consummatory licking in rats: Functional ablation and electrical brain stimulation studies. Proc Natl Acad Sci USA 93:3325-3329

Burns LH, Robbins RW, Everitt BJ (1993): Differential effects of excitotoxic lesions of the basolateral amygdala, ventral subiculum, and medial prefrontal cortex on responding with conditioned reinforcement and locomotor activity potentiated by intra-accumbens infusions of D-amphetamine. Behav Brain Res 55:167-183

Caine SB, Lintz R, Koob GF (1993): Intravenous drug selfadministration techniques in animals. In Sahgal A (ed), Behavioral Neuroscience: A Practical Approach. Vol. 1. Oxford, IRL Press, pp 117-143

Childress AR, Mozley PD, McElgin W, Fitzgerald J, Reivich M, O'Brien CP (1999): Limbic activation during cueinduced cocaine craving. Am J Psychiatry 156:11-18

Ciccocioppo R, Sanna PP, Bloom FE, Weiss F (1999): Environmental cues potently reinstate cocaine seeking behavior and induce c-fos after 3-4 months of abstinence. Soc Neurosci Abstr 25:811

Cornish J, Duffy P, Kalivas PW (1999): A role for nucleus accumbens glutamate transmission in the relapse to cocaine-seeking behavior. Neuroscience 93(4):1359-1367

Davis WM, Smith SG (1976): Role of conditioned reinforcers in the initiation, maintenance and extinction of drugseeking behavior. Pavlov J Biol Sci 11:222-236

de Wit H, Stewart J (1981): Reinstatement of cocaine-reinforced responding in the rat. Psychopharmacology 75:134-143

Ehrman RN, Robbins SJ, Childress AR, O'Brien CP (1992): Conditioned responses to cocaine-related stimuli in cocaine abuse patients. Psychopharmacology 107:523-529

Everitt BJ, Cador M, Robbins TW (1989): Interactions between the amygdala and ventral striatum in stimulus-reward associations: Studies using a second-order schedule of sexual reinforcement. Neuroscience 30:63-75

Everitt BJ, Morris KA, O’Brien A, Robbins TW (1991): The basolateral amygdala-ventral striatal system and conditioned place preference: Further evidence of limbic-striatal interactions underlying reward-related processes. Neuroscience 42:1-18

Everitt BJ, Robbins TW (1992): Amygdala-ventral striatal interactions and reward-related processes. In Aggleton JP (ed), The Amygdala: Neurobiological Aspects of 
Emotion, Memory, and Mental Dysfunction. WileyLiss, New York, pp 401-429

Gaffan D (1992): Amygdala and the memory of reward. In Aggleton JP (ed), The Amygdala: Neurobiological Aspects of Emotion, Memory, and Mental Dysfunction. New York, Wiley-Liss, pp 471-483

Gaffan D, Murray EA, Fabre-Thorpe M (1993): Interaction of the amygdala with the frontal lobe in reward memory. Eur J Neurosci 5:968-975

Gong W, Neill D, Justice JB (1996): Conditioned place preference and locomotor activation produced by injection of psychostimulants into ventral pallidum. Brain Res 707: 64-74

Grant S, London ED, Newlin DB, Villemagne VL, Liu X, Contoreggi C, Phillips RL, Kimes AS, Margolin A (1996): Activation of memory circuits during cue-elicited cocaine craving. Proc Nat Acad Sci USA 93:12040-12045

Harlan RE, Shivers BD, Kow L, Pfaff DW (1983): Estrogenic maintenance of lordotic responsiveness: Requirement for hypothalamic action potentials. Brain Res 268: 67-78

Johnson BA, Chen YR, Schmitz J, Bordnick P, Shater A (1998): Cue reactivity in cocaine-dependent subjects: Effects of cue type and cue modality. Addict Behav 23:7-15

Kelley AE, Smith-Roe SL, Holahan MR (1997): Responsereinforcement learning is dependent on N-methyl-Daspartate receptor activation in the nucleus accumbens core. Proc Natl Acad Sci USA 94:12174-12179

Markou A, Weiss F, Gold LH, Caine SB, Schulteis G, Koob GF (1993): Animal models of drug craving. Psychopharmacology 112:163-182

Maslowski-Cobuzzi RJ, Napier TC (1994): Activation of dopaminergic neurons modulates ventral pallidal responses evoked by amygdala stimulation. Neuroscience 62:11031120

McDonald AJ (1987): Organization of amygdaloid projections to the mediodorsal thalamus and prefrontal cortex: A fluorescence retrograde transport study in the rat. J Comp Neurol 262:46-58

Meil WM, See RE (1996): Conditioned cued recovery of responding following prolonged withdrawal from selfadministered cocaine in rats: An animal model of relapse. Behav Pharmacol 7:754-763

Meil WM, See RE (1997): Lesions of the basolateral amygdala abolish the ability of drug associated cues to reinstate responding during withdrawal from self-administered cocaine. Behav Brain Res 87:139-148

Mogenson GJ, Brudzynski SM, Wu M, Yang CR, Yim CY (1993): From motivation to action: A review of dopaminergic regulation of limbic to nucleus accumbens to ventral pallidum to pedunculopontine nucleus circuitries involved in limbic-motor integration. In Kalivas PW, Barnes CD (eds), Limbic Motor Circuits and Neuropsychiatry. Boca Raton, CRC Press, pp 193-236

Mogenson GJ, Jones DJ, Yim CY (1980): From motivation to action: Functional interface between the limbic system and the motor system. Prog Neurobiol 14:69-97

Narahashi T (1972): Mechanism of action of tetrodotoxin and saxitoxin on excitable membranes. Fed Proc 31:1124-1132

Parkinson JA, Olmstead MC, Burns LH, Robbins TW, Everitt
BJ (1999): Dissociation in effects of lesions of the nucleus accumbens core and shell on appetitive pavlovian approach behavior and the potentiation of conditioned reinsforcement and locomotor activity by D-amphetmine. J Neurosci 19:2401-2411

Paxinos G, Watson C (1997): The Rat Brain in Stereotaxic Coordinates. Compact 3rd Edition. San Diego, Academic Press

Roberts DCS, Corcoran ME, Fibiger HC (1977): On the role of ascending catecholaminergic systems in intravenous self-administration of cocaine. Pharmacol Biochem Behav 6:615-620

Roldan G, Bures J (1994): Tetrodotoxin blockade of amygdala overlapping with poisoning impairs acquisition of conditioned taste aversion in rats. Behav Brain Res 65: 213-219

Schoenbaum G, Chiba AA, Gallagher M (1999): Neural encoding in orbitofrontal cortex and basolateral amygdala during olfactory discrimination learning. J Neurosci 19:18761884

See RE, Grimm JW, Kruzich PJ, Rustay N (1999): The importance of a compound stimulus in conditioned drugseeking behavior following 1 week of extinction from self-administered cocaine in rats. Drug Alcohol Depend 57:41-49

Self DW, Genova LM, Hope BT, Barnhart WJ, Spencer JJ, Nestler EJ (1998): Involvement of cAMP-dependent protein kinase in the nucleus accumbens in cocaine selfadministration and relapse of cocaine-seeking behavior. J Neurosci 18:1848-1859

Sutton MA, Beninger RJ (1999): Psychopharmacology of conditioned reward: Evidence for a rewarding signal at D1-like dopamine receptors. Psychopharmacology (Berl) 144:95-110

Taylor JR, Robbins TW (1986): 6-Hydroxydopamine lesions of the nucleus accumbens, but not of the caudate nucleus, attenuate enhanced responding with rewardrelated stimuli produced by intra-accumbens d-amphetamine. Psychopharmacology (Berl) 90:390-397

Weissenborn R, Yackey M, Koob GF, Weiss F (1995): Measures of cocaine-seeking behavior using a multiple schedule of food and drug self-administration in rats. Drug Alcohol Depend 38:237-246

Whitelaw RB, Markou A, Robbins TW, Everitt BJ (1996): Excitotoxic lesions of the basolateral amygdala impair the acquisition of cocaine-seeking behaviour under a second-order schedule of reinforcement. Psychopharmacology 127:213-224

Wise RA (1998): Drug-activation of brain reward pathways. Drug Alcohol Depend 51:13-22

Zhuravin IA, Brozek G, Bures J (1994): Differential contribution of motor cortex and caudate nucleus to instrumental tongue forelimb synchronization in rats: A functional ablation study. Neuroscience 58:193-200

Zhuravin IA, Bures J (1991): Extent of the tetrodotoxininduced blockade examined by pupillary paralysis elicited by intracerebral injection of the drug. Exp Brain Res 83:687-690

Zito KA, Vickers G, Roberts DCS (1985): Disruption of cocaine and heroin self-administration following kainic acid lesions of the nucleus accumbens. Pharmacol Biochem Behav 23:1029-1036 